\title{
Gastric Neoplasia during Anti-TNF Therapy for Crohn's Disease: Casual Event?
}

\author{
F. M. L. Fortes ${ }^{1}$, B. C. Silva², M. C. Lyra3 , A. M. Pimentel1,3, G. O. Santana ${ }^{2,3}$ \\ ${ }^{1}$ Hospital Geral Roberto Santos, Salvador, Brasil \\ ${ }^{2}$ Hospital Universitário Prof. Edgard Santos (UFBA), Salvador, Brasil \\ ${ }^{3}$ Fundação Monte Tabor, Hospital São Rafael, Salvador, Brasil \\ Email: ${ }^{*}$ florafortes@yahoo.com.br
}

Received 5 July 2015; accepted 10 August 2015; published 13 August 2015

Copyright (C) 2015 by authors and Scientific Research Publishing Inc.

This work is licensed under the Creative Commons Attribution International License (CC BY). http://creativecommons.org/licenses/by/4.0/

(c) (i) Open Access

\section{Abstract}

The increase risk of cancer development in patients with inflammatory intestinal disease (IBD) has already studied for decades. The anti-TNF therapy has changed the treatment strategy of IBD. By using on a larger scale and for a longer time, the anti-TNF raised concern over its potential adverse events. A male Crohn's disease (CD) patient, 55 years old, diagnosed for nine years, treated with infliximab for 6 years. In 2011, he underwent a nupper endoscopy (UE) which showed flat erosive gastritis with moderate intensity in antrum, gastric polyps and gastric erosion. Pathological examination revealed a chronic gastritis in erosive activity and search for Helicobacter pylori resulted positive. In May 2014, the patient was asymptomatic, when it held UE, which showed suggestive lesion of early gastric cancer, measuring $1.5 \mathrm{~cm}$ and search for Helicobacter pylori negative. Histopathological exams confirmed the adenocarcinoma. The patient underwent to a laparoscopic surgery (total gastrectomy with lymphadenectomy and reconstruction Roux-en-Y). Risk factors for the development of gastric cancer in general population are already well defined. However studying a possible association among CD and the different therapeutic modalities used in the treatment of this disease with gastric cancer appearance is important to set specific assessment strategies, prevention and follow-up. While there is no consensus on a proper monitoring for gastric cancer prevention in these patients, individualized conduct, taking into account individual characteristics, family record and other risk factors, should be adopted to avoid unfavorable outcomes in $C D$ patients.

\section{Keywords}

Crohn's Disease, Risk for Neoplasm, Gastric Neoplasm, Anti-TNF

\footnotetext{
${ }^{*}$ Corresponding author.
}

How to cite this paper: Fortes, F.M.L., Silva, B.C., Lyra, M.C., Pimentel, A.M. and Santana, G.O. (2015) Gastric Neoplasia during Anti-TNF Therapy for Crohn's Disease: Casual Event? Journal of Cancer Therapy, 6, 743-747. 


\section{Introduction}

The increase risk of cancer development in patients with inflammatory intestinal disease (IBD) has been studied for decades. It is known that this group of patients have a higher risk of developing certain cancers if compared with the population in general [1].

It is believed that the presence of genetic and environmental factors may contribute to the increase risk of malignancies in these patients, and some features related to the disease itself. Current evidence suggests that the increase risk of colorectal cancer development seems to be directly related to the extent and activity of the inflammatory disease. In turn, the involvement of extra-intestinal malignancies in these patients is still controversial [1].

Tumor necrosis factor (TNF- $\alpha$ ), a proinflammatory cytokine, is now known to play a role in the pathogenesis of Crohn's disease (CD). The anti-TNF therapy has changed the strategy of treating IBD. These drugs can induce mucosal healing and have been shown as being an effective sparing of steroid use in CD active [2]. By using for a longer time, the concern arises about potential adverse events from anti-TNF therapy. Despite a possible risk for the development of malignancies in general, studies after commercializing these drugs have failed in confirming this risk [3].

Less than 3\% of CD patients have gastric involvement by the disease. While a minor part of these cases progresses to gastric cancer after enrollment of the organ by the inflammatory disease, most patients of this cancer were not affected by CD in the upper gastrointestinal tract [4].

We want to discuss how it should be screening and management for patients with CD and gastric cancer.

\section{Case Report}

A 55-year-old man diagnosed with CD for nine years, ileum colonic involvement and not stricture and nonpenetrating behavior without associated comorbidities. At the age of 19 had pulmonary tuberculosis, was treated for 6 months. As a family record, his father had skin cancer at the age of 69 and gastric cancer at 76 years old. He began a treatment with mesalazine, which was used for 1 year without good response and was then replaced by azathioprine, which was used for 6 months, causing diarrhea with blood and mucus. It was introduced thalidomide, the patient used it for a year, but it was suspended when presented significant peripheral neuropathy. Used as maintenance therapy with infliximab for 6 years. The patient had a good response to the treatment with infliximab, asymptomatic, with intestinal movement a day without blood or mucus. During the whole monitoring, he presented laboratory and endoscopic control tests with remission in disease.

In September 2011, the patient was submitted to a UE that showed moderate gastritis erosive flat in antrum, gastric polyps and gastric erosion. Pathological examination revealed a chronic gastritis in erosive activity and search for Helicobacter pylori positive. It was prescribed the treatment for Helicobacter pylori.

In May 2014, during the monitoring colonoscopy, disease in remission was seen in ileum and colon (Figure 1).

Endoscopy on the same date showed gastric ulcer in body posterior wall, ill-defined, high, infiltrating edges with amputated converging pleats, tapered in "clubbing" with deep, irregular and crispy bed, measuring $15 \mathrm{~mm}$ (Figure 2(a) and Figure 2(b)).

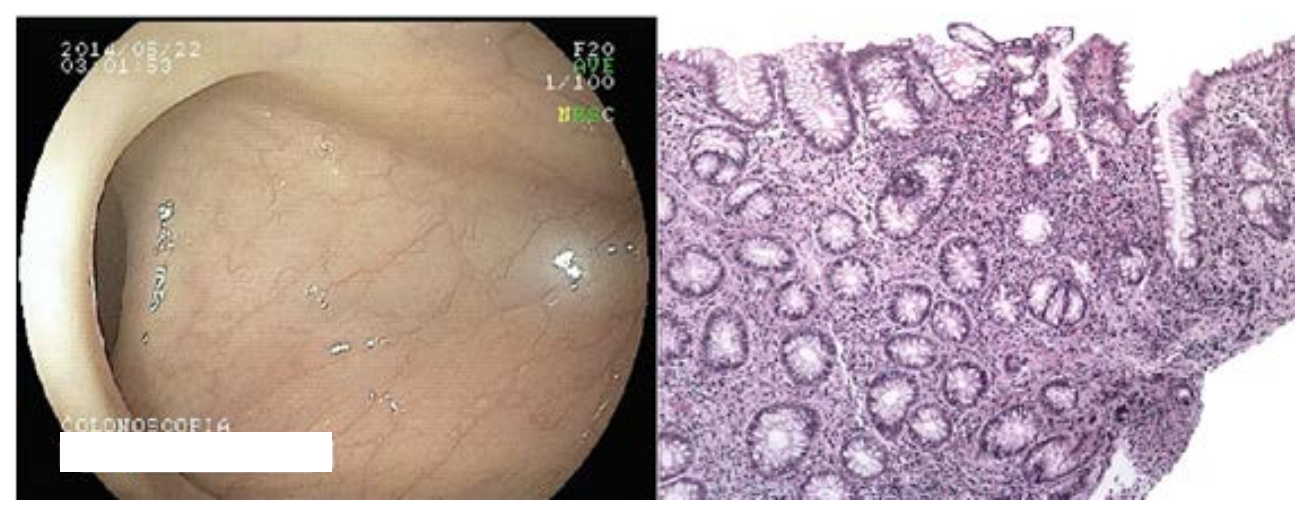

Figure 1. Colonic mucosa with moderate distortion of glandular architecture (glands with varying diameters, irregular spacing) because of fibrosis of the lamina propria and inflammation. 


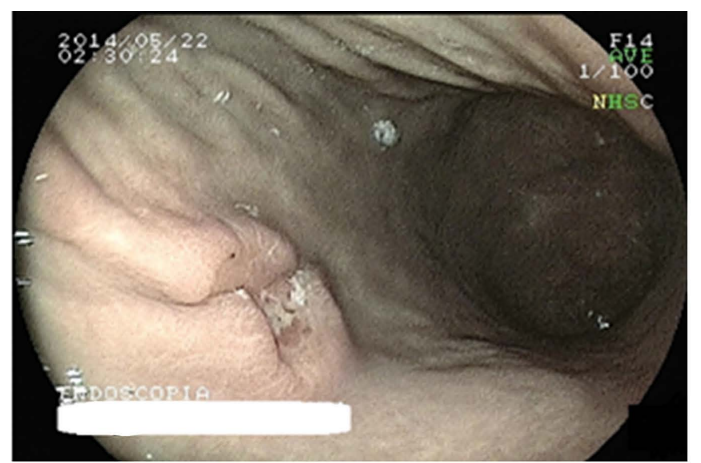

(a)

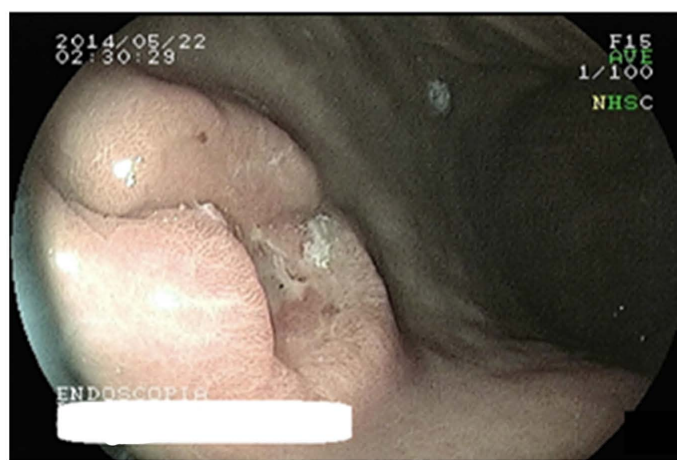

(b)

Figure 2. Gastric ulcer in body posterior wall, ill-defined, high, infiltrating edges with amputated converging pleats, tapered in "clubbing” with deep, irregular and crispy bed, measuring $15 \mathrm{~mm}$.

The pathology showed adenocarcinoma infiltrating type, poorly differentiated cells with signet ring. Search for Helicobacter pylori was negative (Figure 3 and Figure 4).

Patient undergone laparoscopic surgery, total gastrectomy with lymphadenectomy and reconstruction Roux-Y without evidence of macroscopic residual disease in the abdominal cavity.

The pathology revealed undifferentiated adenocarcinoma mucinous, mucocellular, measuring $1.7 \mathrm{~cm}$, type IIC/III without involvement of adjacent lymph nodes (T1N0).

The patient remain without treatment until December/2014, when he started to present diarrhea, abdominal pain, so was decided to reintroduce the anti-TNF for treatment. Now, the patient is asymptomatic, using Infliximab.

\section{Discussion}

The existence of an association between malignancy and DII is already arousing interest among researchers for years. This concern becomes bigger in recent years, especially after the increase use of immunosuppressive drugs in the treatment of these diseases, such as thiopurines and anti-TNF. This report describes the emergence of gastric cancer in a patient with $\mathrm{CD}$ at the age of 55 .

Risk factors for the development of gastric cancer in general population are already well defined. It is important to evaluate a possible association among $\mathrm{CD}$ and the different therapeutic modalities used in the treatment of this disease with gastric cancer. There are several articles questioning the existence of higher risk of developing cancer among CD patients compared to general population. In a study published by Bernstein et al., there was a higher risk of the incidence of cancer in Canadian population affected by DC (IRR $=1.29$; 95\% CI, 1:07 to 1:54) [5]. In turn, Hemminki et al. concluded that the risk of CD patients who were admitted in the hospital to develop tumors was 52\% higher than general population [6]. More recently, a study by Mizushima et al. also demonstrated in t Japanese population the increase of neoplasia risk in patients with CD compared with general population (SIR 2.24\%; 95\% IC 1.19 - 3.83) [1].

The relationship between CD and gastric neoplasia is not established. There are some gastric adenocarcinoma development reports in patients with CD, most of them without gastric involvement [7]-[11]. A causal association is questionable [11]. Mizushima et al., showed a risk of 1.86 (95\% CI 0.22 - 6.69) for gastric cancer in a patient group with DC without involvement of the gastric tract [1].

In general, population with gastric cancer reported in the family, more care is needed, yet, there is no guideline to orient how the follow up should be done. Nam et al., in Korean population, showed an early detection of gastric cancer in patients undergoing to a routine endoscopy. The study suggests that patients with family record of gastric cancer or older than 60 years should undergo endoscopy every 3 years or less [12].

Biological therapy is a major advancement in the treatment of IBD. The antagonist of the tumor necrosis factor is shown highly effective in the induction and maintenance of remission in CD [2]. Using larger scale and a more prolonged anti-TNF therapy arises concern about their adverse events in long-term. The possible role of the biological development of solid tumors is not well characterized. Andersen et al. (2014) showed no increased risk of solid cancer development in patients exposed to anti-TNF therapy, at a median follow-up of 3.7 years [13].

We do not know if the western population must do it and how a possible screening for gastric cancer should be done. What are the real risk factors to be considered? Until now, we have no answer whether there is an 


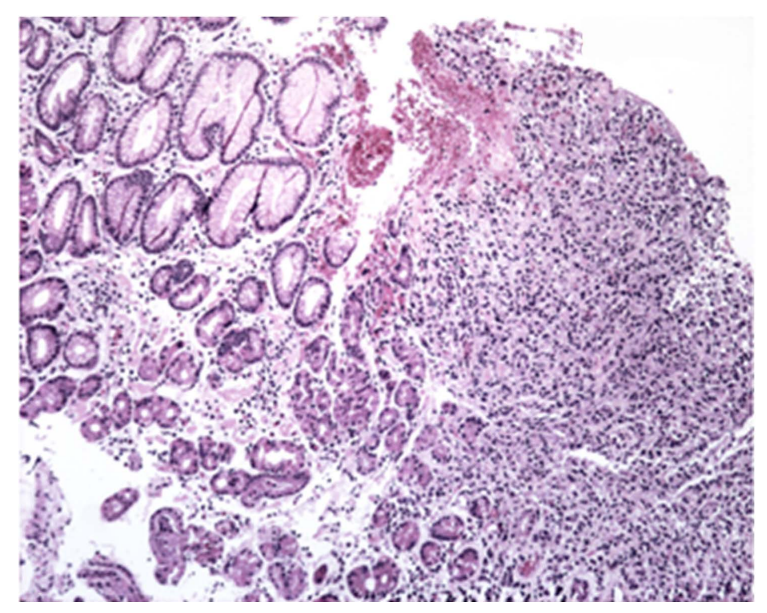

Figure 3. Gastric mucosa of the fund/body type. On the left half nonneoplastic mucosa. Right halfway mucosa with cancer (adenocarcinoma infiltrating type, poorly differentiated signet ring cells).

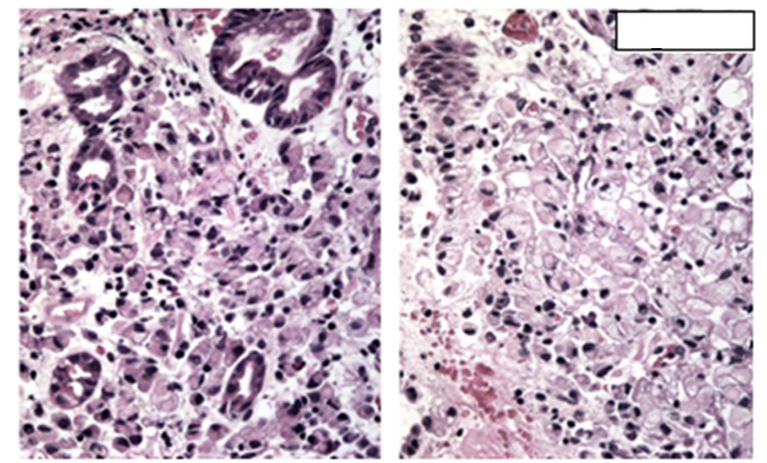

Figure 4. Gastric mucosal fund/body type. On the left half non-neoplastic mucosa. Right halfway mucosa with cancer (adenocarcinoma infiltrating type, poorly differentiated, with signet ring cells, infiltrating the lamina propria and decoupling non-neoplastic gastric glands).

association between CD and gastric neoplasia, and under what conditions this association could occur. The presence of stomach affecting disease would have a role. Would a systematic screening be valid? In addition, in those individuals with a family record of gastric cancer with CD? Moreover, in those individuals with CD, family record and continuous use of anti-TNF? Possibly long-term prospective studies with large cohorts of patients with CD may help us to define these behaviors. By now, an individualized and insightful observation is recommended for these patients.

\section{Conclusion}

The presence of gastric involvement is not established as an unquestionable risk factor for gastric cancer in patients with $\mathrm{CD}$, instead of gastric cancer in these patients which is questioned as an incidental finding in most of them. The presence of family record is an important risk factor for gastric cancer, but when the patient is over 70 years old, this risk becomes questionable. H. pylori presence is already a known risk factor for gastric cancer, but once the patient is treated and normal control is done, there is no consensus on how this should be followed. On the other hand, prolonged use of anti-TNF therapy is not well defined as independent risk factor for gastric cancer. Our patient had a prolonged use of anti-TNF therapy, record of familiar gastric cancer and gastric adenocarcinoma diagnosed when he had the disease under control. This case raises the question of how it should be carried out monitoring the patients using anti-TNF therapy and family record of gastric cancer, although with advanced age in relative. We currently have many questions and few answers. By now, an individualized and insightful observation is recommended for these patients, taking into account individual characteristics, family 
record among other risk factors, while maintaining vigilance in CD patients with long history of illness. Doubts exist and studies need to be conducted for a better understanding of the true risk of gastric cancer in these individuals.

\section{References}

[1] Mizushima, T., Ohno, Y., Nakajima, K., Kai, Y., Iijima, H., Sekimoto, M., Nishida, T., et al. (2010) Malignancy in Crohn's Disease: Incidence and Clinical Characteristics in Japan. Digestion, 81, 265-270. http://dx.doi.org/10.1159/000273784

[2] Song, Y., Zheng, P., Xiao, J. and Lu, Z. (2014) Efficacy and Safety of Adalimumab for the Crohn's disease: A Systematic Review and Meta-Analysis of Published Randomized Placebo-Controlled Trials. European Journal of Clinical Pharmacology, 70, 907-914. http://dx.doi.org/10.1007/s00228-014-1702-1

[3] Mendes, D., Alves, C. and Batel-Marques, F. (2014) Safety Profiles of Adalimumab, Etanercept and Infliximab: A Pharmacovigilance Study Using a Measure of Disproportionality in a Database of Spontaneously Reported Adverse Events. Journal of Clinical Pharmacy and Therapeutics, 39, 307-313. http://dx.doi.org/10.1111/jcpt.12148

[4] Estlein, D., Ohana, G., Weil, R., Rath-Wolfson, L. and Wolloch, Y. (2001) Early Cancer in Gastric Crohn’s Disease. IMAJ, 3, 379-380.

[5] Bernstein, C., Blanchard, J., Kliewer, E. and Wajda, A. (2001) Cancer Risk in Patients with Inflammatory Bowel Disease. Cancer, 91, 854-862. http://dx.doi.org/10.1002/1097-0142(20010215)91:4<854::AID-CNCR1073>3.0.CO;2-Z

[6] Hemminki, K., Li, X., Sundquist, J. and Sundquist, K. (2009) Cancer Risks in Crohn Disease Patients. Annals of Oncology, 20, 574-580. http://dx.doi.org/10.1093/annonc/mdn595

[7] Hudesman, D., Lichtiger, S. and Sands, B. (2013) Risk of Extraintestinal Solid Cancer with Anti-TNF Therapy in Adults with Inflammatory Bowel Disease: Review of the Literature. Inflammatory Bowel Diseases, 19, 644-649. http://dx.doi.org/10.1097/MIB.0b013e318280ebbd

[8] Persson, P.G., Karlén, P., Bernell, O., Leijonmarck, C.E., Broström, O., Ahlbom, A. and Hellers, G. (1994) Crohn’s Disease and Cancer: A Population-Based Cohort Study. Gastroenterology, 107, 1675-1679.

[9] Andersen, N. and Jess, T. (2013) Has the Risk of Colorectal Cancer in Inflammatory Bowel Disease Decreased? World Journal of Gastroenterology, 19, 7561-7568. http://dx.doi.org/10.3748/wjg.v19.i43.7561

[10] Lutgens, M.W.M.D., Oijen, M.G.H., van der Heijden, G.J.M.G., Vleggaar, F.P., Siersema, P.D. and Oldenburg, B. (2013) Declining Risk of Colorectal Cancer in Inflammatory Bowel Disease: An Updated Meta-Analysis of Population-Based Cohort Studies. Inflammatory Bowel Diseases, 19, 789-799. http://dx.doi.org/10.1097/MIB.0b013e31828029c0

[11] Ikeuchi, H., Kusunoki, M., Yamamura, T. and Nishigami, T. (2002) Crohn’s Disease Associated with Gastric Cancer. Journal of Gastroenterology, 37, 47-49. http://dx.doi.org/10.1007/s535-002-8132-6

[12] Nam, J.H., Choi, J., Cho, S., Kim, C.G., Jun, J.K., Choi, K.S., et al. (2012) Association of the Interval between Endoscopies with Gastric Cancer Stage at Diagnosis in a Region of High Prevalence. Cancer, 118, 4953-4960. http://dx.doi.org/10.1002/cncr.27495

[13] Andersen, N.N., Pasternak, B., Basit, S., Andersson, M., Svanström, H., Caspersen, S., et al. (2014) Association between Tumor Necrosis Factor- $\alpha$ Antagonists and Risk of Cancer in Patients with Inflammatory Bowel Disease. JAMA, 311, 2406-2413. http://dx.doi.org/10.1001/jama.2014.5613 